\title{
Academia Brasileña de Historia de la Enfermería: 2007 a 2014
}

\section{Brazilian Academy of Nursing History: 2007 to 2014 Academia Brasileira de História da Enfermagem: 2007}

\section{a 2014}

\author{
Fábio Soares de Meloํㅡ, Genival Fernandes de Freitas², Bárbara \\ Barrionuevo Bonini ${ }^{3}$
${ }^{1}$ Mestrando em Enfermagem pela Escola de Enfermagem da Universidade de
São Paulo. Correo electrónico: fabio.soares.melo@usp.br
2Professor Titular junto ao Departamento de Orientação Profissional da Escola
de Enferamgem da Universidade de São Paulo. Correo electrónico:
genivalf@usp.br
${ }^{3}$ Professor por tempo determinado junto ao Departamento de Orientação
Profissional da Escola de Enferamgem da Universidade de São Paulo. Correo
electrónico:bonini@usp.br

Cómo citar este artículo en edición digital: Melo, F.S., Freitas, G.F. \& Bonini, B.B. (2019). Academia

Brasileña de Historia de la Enfermería: 2007 a 2014. Cultura de los Cuidados (Edición digital), 23

(54). Recuperado de http://dx.doi.org/10.14198/cuid.2019.54.14

Correspondencia: Avenida Queiróz Pedroso, n.ํ562, apartamento 710, Jardim Pedroso, Mauá, Estado de São Paulo, CEP 09370-360

\section{Correo electrónico de contacto: fabio.soares.melo@usp.br Recibido: 20/011/2019; Aceptado: 20/01/2019}

\section{(c)}

\begin{abstract}
This study aims to understand how, why and for what reason, a group of nurses and History of Nursing researchers chose to create the Brazilian Academy of Nursing History in 2010. This study aimed to describe motivations and expectations of the nurses and researchers in this field as well as to identify the historical circumstances, struggles and political forces involved in the creation of institution. It is observed that the social actors involved in the creation of the entity came from the Research Group "History and Legislation of Nursing" and that political forces and struggles were among researchers in the history of nursing because there were disparate interests in the
\end{abstract}

creation of this entity. Among the contributions of the Academy is the fight for the continuity of teaching nursing history in the universities, and the 2007 IberoAmerican Symposium on Nursing History that was the propulsion for its creation.

Keywords: Nursing, nursing history, professional identity, qualitative research, social actors.

\section{RESUMO}

Este estudo objetiva compreender como, por quê e para que, um grupo de enfermeiros e pesquisadores da História da Enfermagem optou pela criação da Academia Brasileira de História da Enfermagem, em 2010. Este estudo 
objetivou descrever as motivações e expecativas dos enfermeiros $\mathrm{e}$ pesquisadores nesse campo, bem como identificar as circunstâncias históricas, lutas e forças políticas envolvidas na criação dessa instituição. Observa-se que os atores sociais envolvidos na criação da entidade eram provenientes do Grupo de Pesquisa "História e Legislação da Enfermagem" e que as forças e lutas políticas davam-se entre os pesquisadores da história da enfermagem pois havia interesses díspares na criação dessa entidade. Dentre as contribuições da Academia destaca-se a luta pela continuidade do ensino da história da enfermagem nas instituições formadoras, sendo a realização do I Simpósio Ibero Americano de História da Enfermagem, em 2007, a propulsão para sua criação.

Palavras chave: Enfermagem, história da enfermagem, identidade profissional, pesquisa qualitativa, atores sociais.

\section{RESUMEN}

Este estudio tiene el objetivo de comprender cómo, por qué y para qué, un grupo de enfermeros e investigadores de la Historia de la Enfermería optó por la creación de la Academia Brasileña de Historia de la Enfermería en 2010. Los objetivos específicos del estudio fueron describir las motivaciones y expectativas de los enfermeros y pesquisadores de ese campo, asimismo, identificar las circunstancias históricas, luchas y fuerzas políticas involucradas en la creación de esa institución. Se observa que los actores sociales involucrados en la creación de la entidad provenían del Grupo de Investigación "Historia y Legislación de la Enfermería" y que las fuerzas y luchas políticas se daban entre los investigadores de la historia de la enfermería pues tenían intereses diferentes en la creación de esa entidad. Entre las contribuciones de la Academia se destaca la lucha por la continuidad de la enseñanza de la historia de la enfermería en las instituciones formadoras siendo la realización del I Simposio Iberoamericano de Historia de la Enfermería en 2007 la propulsión para su creación.

Palabras clave: Enfermería, historia de la enfermería, identidad profesional, investigación cualitativa, actores sociales.

\section{INTRODUÇÃO}

Tendo como princípio que nenhuma instituição se cria se os personagens envolvidos na história não estejam motivados para realizar tal desafio, buscase, neste estudo, entender como, por que e para que enfermeiros e pesquisadores da História da Enfermagem decidiram criar uma Academia Brasileira de História da Enfermagem, identificando as circunstâncias históricas, possíveis campos de lutas e forças políticas envolvidas na criação e desenvolvimento dessa entidade.

Segundo Löw (2013) na elaboração de trabalhos científicos a história constitui importante base para rever caminhos já percorridos, na busca de lacunas a serem analisadas, no aprofundamento de estudos ou de reflexões temáticas, para destacar a origem de um acontecimento ou iniciar uma reflexão sobre diversas temáticas. Todavia, mais que uma narrativa linear, introdutória ou sobre acontecimentos notáveis, a história deve problematizar contextos históricoculturais, bem como fundar suas análises a partir de evidências, registros ou sinais, que permitam o acesso a outras possibilidades de interpretação do passado.

Oguisso (2014) diz que pensar o passado como mola propulsora para a arte e a ciência 
do cuidado reside no entendimento de que nenhuma ocupação pode ser compreendida inteligentemente sem ter sido, em alguns de seus aspectos, analisada do ponto de vista histórico e interpretada do ponto de vista humano, pois caso contrário perderia sua condição de ciência.

Em relação à Enfermagem:

"É uma profissão que ao longo do tempo vem desconstruindo e construindo sua história [...]. E sua relação com a sociedade é permeada pelos conceitos, preconceitos e estereótipos que se estabeleceram na sua trajetória histórica e que influenciam até hoje a concepção do que é, a que vem e qual o seu significado enquanto profissão da saúde composta de gente que cuida de gente" (Padilha, Nazario \& Moreira, 1997, p. 308).

Campos, Porto, Oguisso e Freitas (2008) defendem que a História da Enfermagem vem se impondo como tema emergente obrigatório, urgente e necessário no campo da profissão, dado que outros setores da prática profissional de enfermagem têm alcançado elevada cientificidade intelectual, grande produtividade e a plena maturidade tecnológica, talvez, por isso mesmo, com certo reconhecimento social. Segundo ele, os determinantes humanísticos, históricosociais e político-culturais da enfermagem não foram ainda suficientemente analisados e continuam pouco explorados.

Barreira e Baptista (2003) nos diz que o que se entende por enfermagem é uma construção histórica e coletiva, marcada por rupturas, as quais, no entanto, não significam o apagamento do passado e o desconhecimento do que então foi construído. O estudo da História da Enfermagem, ao lançar um novo olhar sobre a trajetória da profissão na sociedade brasileira, é um instrumento vital para a busca de respostas às demandas sociais do presente.
Deste modo, esta pesquisa tem como objetivos descrever as motivações e expectativas dos enfermeiros e pesquisadores da História da Enfermagem para a criação da Academia Brasileira de História da Enfermagem (ABRADHENF) em 2010 e identificar as circunstâncias históricas, as lutas e forças políticas envolvidas na criação e desenvolvimento dessa entidade.

\section{MÉTODO}

Optou-se pelo recorte temporal de 2007 a 2014, por duas razões: a primeira refere-se à realização do I Simpósio Ibero Americano de História da Enfermagem, organizado pela Profa Dra Taka Oguisso, da Escola de Enfermagem da Universidade de São Paulo (EEUSP), no qual aglutinaram-se pesquisadores provenientes da Europa, Ásia e América Latina, no entorno das temáticas: Antropologia dos cuidados, História das instituições e História de vida, culminando com a celebração de um Fórum de Pesquisadores em História da Enfermagem. A segunda razão, refere-se aos anos de 2010, quando se consolidou a ABRADHENF com a sua fundação legal e 2014, quando finalizou a primeira gestão eleita da referida entidade.

Trata-se de um estudo histórico social de abordagem qualitativa. Para consecução da presente investigação foram utilizadas fontes primárias, após a autorização formal da Presidência da ABRADHENF para o manuseio dos seguintes documentos: a) Acervo do Centro Histórico Cultural da Enfermagem Ibero Americana da EEUSP; b) Regimento da Fundação da Academia; c) Registro Notorial; d) Ata da Assembleia Fundacional; e) Ata das Assembleias Ordinárias e Extraordinárias da Diretoria dessa Entidade; f) Atas dos Simpósios Ibero- 
Americanos de História da Enfermagem e g) correios eletrônicos. Também foram utilizados, como fontes secundárias, os trabalhos acadêmicos que versem sobre a temática da História da Enfermagem e entidades de classe da enfermagem brasileira.

Após levantamento das informações contidas nos documentos acima descritos foi realizada uma profunda análise das mesmas para organizá-las consoante os objetivos propostos na pesquisa.

No que tange à abordagem qualitativa da pesquisa González (2016) afirma que o planejamento metodológico supõe que o desenho de investigação considere a fundamentação teórica do problema; formulação de hipóteses; revisão bibliográfica necessária para elaborar-se $\mathrm{o}$ estudo da questão; descrição da importância do trabalho para a temática escolhida de acordo com a constatação alcançada sobre o objeto de estudo.

Para problematizar os dados, o investigador pode utilizar-se da historiografia ou fazer uma tese historiográfica, o que exige saber o que se busca (o objeto da investigação), ou seja, a definição de uma situação histórica que se configure na possibilidade de realização de uma pesquisa. A problematização é um ponto de partida para o trabalho, e não apenas uma ideia inconclusa relativa à historiografia ou aos livros que já foram escritos. (Padilha \& Boresntein, 2005).

\section{RESULTADOS E DISCUSSÃO}

Os resultados revelaram as motivações e as expectativas dos enfermeiros $\mathrm{e}$ pesquisadores do campo da história da enfermagem em prol do desenvolvimento da ABRADHENF, a qual se consolidou como uma entidade real, como se pode observar no excerto referente a correio eletrônico seguinte trocado entre membros do Grupo de Pesquisa:

"Ficamos nesse impasse e discutindo o assunto com o Fernando Porto e Welington da UNIRIO e o Paulo e Genival em SP, chegamos à conclusão que teríamos que criar uma associação de Historia da Enfermagem aqui, entre nós. [...] A proposta do Fernando era que se criasse essa associação em SP em agosto para comemorar os 100 anos da morte de Florence. [...] prefere que seja em SP por termos melhor estrutura para enfrentar "essa barra". [...] A ideia me parece é ampliar e trazer gente do Brasil todo, para dar suporte à nova associação. Tenho certeza que dentro e fora da enfermagem acharão aliados" (T. Oguisso, comunicação pessoal, 23 de fevereiro de 2010).

No excerto acima os nomes citados, Fernando Ramos Porto e Wellington Mendonça Amorin, ambos pesquisadores da Escola de Enfermagem Alfredo Pinto Universidade Federal do Estado do Rio de Janeiro (UNIRIO) e os professores Paulo Fernando de Souza Campos que integrava, à época, o Grupo de Pesquisa "História e Legislação da Enfermagem" da EEUSP como pós-doutorando na área da História da Enfermagem, e Genival Fernandes de Freitas atualmente pesquisador da EEUSP.

A ideia originária era a criação de uma associação de história da enfermagem que congregasse pesquisadores interessados nesse campo, no Brasil. Essa ideia foi-se construindo até a sua consolidação definitiva, em 2010, com a gênese oficial de Academia Brasileira de História da Enfermagem. Cabe destacar que, desde a realização do I Simpósio Ibero-Americano de História da Enfermagem (I SIAHE), em São Paulo, em 2007, organizado pela EEUSP, sob o patrocínio da Fundação de Amparo à Pesquisa do Estado de São Paulo, vinha 
sendo engendrada aquela ideia da criação de uma entidade que aglutinasse pesquisadores do campo da história, alunos de graduação e de pós, e outros atores sociais como historiadores, etc.

O I SIAHE alavancou as questões da História da Enfermagem nos âmbitos brasileiro e ibero-americanao, pois propiciou um encontro entre pesquisadores de vários países, destacando-se: Espanha, Portugual, Brasil, Chile, Peru, México, Argentina, dentre outros. Após o evento referido, coordenado pela Profa. Taka Oguisso, a época profa pela EEUSP, houve a continuação do debate sobre o regimento para a criação da ABRADHENF, culminando com a sua fundação, de maneira formal, em 2010.

Além da fundação da Academia, vale pontuar a consolidação da série histórica dos eventos em História da Enfermagem com o II SIAHE em Lisboa, em 2009; o III em Alicante, Espanha, em 2011; o IV na Cidade do México, em 2013. Em 2015, não houve o evento (que seria o V) na Colômbia, sob a alegação de dificuldades financeiras e de patrocínio para a sua consecução junto à Universidade Nacional, daquele país. Em 2016 aconteceu o V SIAHE, em Granada, Espanha, junto à Fundação Index. Proximamente, ocorrerá o VI SIAHE, na Costa Rica.

Dentro do grupo de pesquisa em "História e Legislação em Enfermagem", da EEUSP, era unânime a ideia de se criar esta Academia, urgentemente, a fim de dar mais alento e fôlego às pesquisas na área da História da Enfermagem, valorizar esse campo do saber, buscar novos financiamentos para essa área do conhecimento e favorecer as trocas de experiências entre os pesquisadores.

As motivações e expectativas que os atores sociais envolvidos na criação da referida entidade traziam consigo materializaram-se no Estatuto da Academia cujos objetivos foram delineados em seu artigo 2..

“a) Estimular o interesse e a mútua colaboração em História da Enfermagem; b) Promover a educação de enfermeiros e do público, em geral, com relação à história e ao legado da profissão de enfermagem; c) Apoiar pesquisas em História da Enfermagem para que alcancem nível de excelência nesse campo do saber; d) Incentivar a guarda, coleção, preservação e uso de documentos de importância histórica para a enfermagem; e) Divulgar estudos históricos sobre enfermagem através de mostras ou exposições de objetos e documentos e servir como fonte de informação sobre História da Enfermagem; f) Produzir e distribuir material educacional relacionado com a História de Enfermagem e o legado da profissão de enfermagem; g) Promover elou fortalecer a inclusão do conteúdo da História da Enfermagem no currículo dos cursos de graduação, pós-graduação e de nível médio de enfermagem; h) Fomentar a colaboração interdisciplinar em História com todas as ciências e saberes afins; i) Reconhecer profissionais que contribuiram com suas realizações para a História da Enfermagem como membros honorários, outorgando-lhes um título honorífico apropriado segundo critérios especificados em Regimento Interno; j) Organizar eventos, exposições e reuniões científicas para intercâmbio de estudos e informações entre seus membros e os de outras entidades similares de nível nacional ou internacional; k) Manter publicação periódica, impressa ou virtual, com informações e textos inéditos/originais de pesquisadores, membros individuais ou em grupo; l) Apoiar grupos de pesquisa de História da Enfermagem cadastrados, ou não, em órgãos de fomento à pesquisa científica; m) Integrar entidades internacionais de História da Enfermagem e áreas afins" (Academia Brasileira de História da Enfermagem [ABRADHENF], 2010). 
A criação da Academia foi fundante para o alcance de um anseio dos pesquisadores citados anteriormente, qual seja, o de dar visibilidade às raízes históricas da profissão e de fomentar estudos e trabalhos dedicados à História da Enfermagem, tão claramente expressos em seu regimento podendo ser observado através do excerto da Ata da 1. ${ }^{\text {a }}$ Assembleia Geral da entidade:

"A presidente relatou as diversas atividades já realizadas pelos membros da diretoria: a) participação na Conferência Internacional de História da Enfermagem, ocorrida em Londres, Inglaterra, nos dias treze a dezesseis de setembro do corrente ano, com apresentação de trabalhos de Taka Oguisso e Luciana Barizon Luchesi, da diretoria da Academia; b) participação na reinauguração do $\mathrm{Museu}$ Florence Nightingale, em Londres, Inglaterra; c) $V$ Congresso Científico de Enfermagem, Nacional e Internacional, em La Paz, Bolívia, nos dias vinte e um a vinte e quatro de setembro do corrente ano, representado pela presidente Taka Oguisso" (Kuntze, 2010, p. 2).

Em eventos nacionais observa-se a participação dos membros da entidade conforme fragmento abaixo da Ata da 1. Assembleia Geral:

“ [...] a Presidente comunicou também a participação em Cuiabá, do IV Encontro do Conselho Regional de Enfermagem de Mato Grosso, Encoren-MT, no dia primeiro de setembro passado, ministrando conferência de abertura do evento; Comemoração dos cento e vinte anos da Escola de Enfermagem Alfredo Pinto, da Universidade Federal do Estado do Rio de Janeiro, UNIRIO, na cidade do Rio de Janeiro, em setembro de dois mil e dez" (Kuntze, 2010, p. 2).

A criação da entidade, conforme observação em mesmo documento, alcançou projeção internacional com a divulgação de sua fundação em revistas como Hyades, na
Espanha, e Bulletin, da Associação Americana de História da Enfermagem, nos Estados Unidos, configurou o reconhecimento, por parte dassas instituições, da importância da recém criada entidade no tocante às questões que envolvem a temática da História da Enfermagem.

Ainda em consonância com o objetivo traçado de fomentar estudos e publicações acerca da temática observou-se que no primeiro ano de atuação da academia já ocorreu o lançamento do livro, organizado pelos professores doutores Fernando Rocha Porto e Wellingtom Mendonça Amorim, História da Enfermagem: identidade, profissionalização e símbolos, durante o evento dos 120 anos da Escola de Enfermagem Alfredo Pinto-UNIRIO.

Em outro documento analisado, a Ata da Reunião Extraordinaria, notou-se a importância da constituição de parcerias para a fundação da ABRADHENF, com destaque ao apoio oferecido pelo Conselho Regional de Enfermagem do Estado de São Paulo (COREN-SP) à época:

"Dando início, a presidente apresenta a proposta de plano de trabalho exigida como contrapartida do Conselho Regional de Enfermagem - COREN-SP para a utilização do espaço para escritório de representação da ABRADHENF, junto ao Centro de Aperfeiçoamento Profissional da EnfermagemCAPE/COREN-SP, à Rua Dona Veridiana, 298, São Paulo, que consiste de duas (2) salas equipadas com armários, mesa, cadeiras, computadores e ramal telefônico, servido ainda de ar condicionado e som ambiente, localizado no primeiro piso do CAPE/COREN-SP" (Campos, 2010, p. 1).

Sendo assim, a Academia propôs, em contrapartida, e foi aprovado pelo CORENSP, um projeto sobre "Representações 
Sociais da Enfermagem no Cinema", com a apresentação mensal de um filme, seguida de debate, aberto a todo o público interessado, sem ônus. Vale destacar que o referido projeto alcançou êxito, com um número cada vez mais crescente de pessoas interessadas, graças à divulgação antecipada da programação pelo próprio Conselho. Além do projeto referido, a Academia também realizou junto ao Conselho um Colóquio sobre a História da Enfermagem e um Seminário de Educação e Pesquisa.

Os membros da Academia mostravam-se empenhados, conforme observado nos documentos analisados, em manter publicações inéditas que contribuíssem para os estudos e trabalhos voltados à história da enfermagem, bem como defendiam a atuação de professores em história da enfermagem nos cursos de capacitação profissional e capacitação para docentes, conforme excerto da Ata da 2. ${ }^{\text {a }}$ Assembleia Geral da ABRADHENF:

"Dr. Wellington Amorim considerou que era necessário trazer produções novas, textos originais, resultados de pesquisa para não haver repetição de textos e análises. [...] Dr. Gilberto Tadeu ressaltou a importância da participação de professores de história da enfermagem, para capacitação docente, [...] Dra. Taka relatou sobre dois cursos específicos, de 08 a 12 ou 16 hs de duração, oferecidos para enfermeiros/docentes de História da Enfermagem com limitação de 10 vagas" (Campos, 2011, p. 3).

Vale destacar que o personagem referido no excerto trata-se do Prof. Dr. Gilberto Tadeu Reis da Silva, docente da Escola de Enfermagem da Universidade Federal da Bahia (UFBA).

Dentre as instituições da enfermagem, no cenário nacional, que passaram a se interessar pela Academia, destacam-se: Universidade Federal da Bahia, Escola de Enfermagem de Ribeirão Preto-USP, ABen Nacional e Universidade Adventista de São Paulo. Vale pontuar que essas parcerias constituíram-se em ganhos para a temática da história da enfermagem ocorrendo, por exemplo, a partir delas, o lançamento do livro Ivete Oliveira-ícone da Enfermagem Brasileira, cuja edição havia sido feita em parceria da ABRADHENF com a UFBA. Soma-se a isso a parceria entre pesquisadores da Academia com o Museu Nacional de Enfermagem Ana NeriMUNEAN, sediado, até então, em Salvador (BA), com o propósito de alavancar o desenvolvimento de projetos educativos e culturais sobre história da enfermagem.

A ideia de se criar um espaço para discussões e debates em história da enfermagem, o que hoje é a ABRADHENF, com o intuito de tentar "entender o passado dessa profissão e como ela desenvolveu-se através do tempo até os dias atuais teve início na década de oitenta com a profa Dra Amália Correa de Carvalho" (Oguisso, 2015), adiquiriu o impulso necessário duas décadas depois através dos membros do grupo de pesquisa "História e Legislação de Enfermagem" cujo desejo maior era a criação da Federação Ibero-Americana de História da Enfermagem (FIHAE).

E, apesar de a criação da ABRADHENF não ter sido a ideia primeira, conforme verificado nos documentos analisados, sua fundação serviu para impulsionar os trabalhos e estudos ligados à história da enfermagem, constituindo-se num importante pólo de disseminação das ideias, estudos, pesquisas, debates acerca da temática e como esta influenciou, e ainda influencia os comportamentos e atitudes como profissionais de enfermagem.

Os primeiros anos de existência da 
Academia foram de intensa produção de conhecimentos neste campo do saber. Seus membros empenharam todos os esforços necessários para a disseminação desses conhecimentos através de cursos, simpósios, seminários e publicações, procurando contemplar cada uma das alíneas expressas em seu artigo 2. . refletindo sua razão de existir, sua missão.

Importante destacar, também, o interesse de seus membros em manter um canal aberto de comunicação e interação com outros pesquisadores da área, sendo através de participações em congressos nacionais e internacionais, ou, sendo na formação de agentes multiplicadores em cursos oferecidos pela entidade aos demais profissionais interessados.

Outro aspecto relevante foram as parcerias que a Academia constituiu em sua trajetória inicial, que ajudaram a alicerçar essa entidade por acreditarem em seus ideais e por estarem convictos de que a Academia contribuiria, em muito, para os estudos nesta área de conhecimento. Exemplos de parcerias foram as firmadas com a EEUSP que concordou em ceder espaço físico para acomodar o escritório da entidade bem como abrigar a página da ABRADHENF em seu site; com o COREN-SP que de imediato prontificou-se, também, em ceder um espaço físico e em contrapartida propôs à entidade a realização de cursos para os profissionais de enfermagem, desafio de imediato aceito pelos membros; com o COFEN; entre outras instituições.

Percebe-se a necessidade de maior divulgação das atividades da Academia, a fim de atrair novos interessados, especialmente entre graduandos e pósgraduandos da enfermagem e de áreas afins, como a História. Essa é uma das limitações atuais, pois vê-se que ainda há um exíguo número de associados, em torno de 30 pesquisadores inscritos. No entanto, acredita-se que a divulgação do que é a Academia poderá angariar novos adeptos.

Inegavelmente tudo que foi produzido pela ABRADHENF, no periodo de 2010 a 2014, foi relevante para os estudos na área da história da enfermagem e contribuiu para o engrandecimento da profissão. E ainda, fazse mister, a citação de dois importantes desdobramentos ocorridos com a sua criação, a saber, o grande apoio dado para a criação da FIHAE, em 2014, com sede na cidade de México, da qual é associada. Configurando que a internacionalização dos estudos em História da Enfermagem não só fortaleceram os mecanismos de cooperação e colaboração entre seus membros associados como também favoreceram a complementariedade de forças e recursos entre instituições situadas em diferentes realidades, propiciando um enriquecimento continuo e mútuo de oportunidades de novos conhecimentos.

$\mathrm{O}$ segundo desdobramento foi a Reinauguração do Centro Histórico Cultural da Enfermagem Ibero-Americana (CHCEIA), em 2015, responsável por manter viva e preservada a história da formação da idendidade profissional da enfermagem através de seu riquíssimo acervo.

\section{CONCLUSÃO}

A fundação da Academia inaugurou um importante espaço para debates e estudos sobre a história da enfermagem cujo passado, ainda mal compreendido pelos profissionais que a exercem, encontrou um importante elo para ligar-se ao presente, tornando-se mais compreensível. Passado que se reflete, ainda hoje, em nosso modo de ver e pensar a profissão, ganhando voz e fazendo-se ouvir em nosso presente para que, assim, possamos entendê-lo e 
constituirmos em agentes transformadores.

A ABRADHENF foi o primeiro elemento de uma cadeia de transformações envolvendo a temática, atuando na promoção de debates em congressos como o Simpósio Ibero Americano de História da Enfermagem, na multiplicação de conhecimentos através dos cursos oferecidos a profissionais da área interessados em ampliar seus saberes, nas publicações de artigos e livros. A partir dessas experiências seus membros constituíram-se em atores sociais relevantes na formação da identidade profissional da categoria e para as futuras gerações de enfermeiros.

O resgate da história da enfermagem, feito através da memória e de outras fontes documentais, são relevantes, na medida em que fornecem subsídios para uma maior compreensão acerca da profissão no contexto social em que está inserida, bem como, possibilita a tentativa de fornecer respostas a alguns questionamentos, tais como, afinal quem somos? O que realmente desejamos? E, qual direção vislumbramos?

A finalidade à qual se propõe uma entidade, declarada em Estatuto, somente é alcançada quando estes objetivos são perseguidos com toda dedicação e afinco e postos em prática. E isto, é perfeitamente visível no caso da ABRADHENF, cuja busca incessante em difundir suas ideias, em promover conhecimento e alcançar o máximo possível de profissionais da área está muito bem alicerçada em suas ações, sendo possível constatar o quão esta entidade contribuiu, e ainda contribui, para elevar a história da enfermagem e a categoria profissional a um patamar ainda mais significativo para a coletividade.

\section{REFERÊNCIAS}

- Academia Brasileira de História da Enfermagem (ABRADHENF). (2010). Estatuto [internet]. Recuperado de http://www.abradhenf.com.br/ptbr/institucional.

- Barreira, I. A. \& Baptista, S. S. (2003). O Movimento de Reconsideração do Ensino e da Pesquisa em História da Enfermagem. Revista Brasileira de Enfermagem, 56(6), 702-706.

- Campos, P.F.S., Porto, F., Oguisso, T. \& Freitas, G.F. (2008). Memória da Saúde em São Paulo: Centro Histórico Cultural da Enfermagem Ibero-Americana. Cadernos de História da Ciência, 4(I), 39-52.

- Campos, P. F. S. (novembro, 2010). Ata da Reunião Extraordinaria. Academia Brasileira de História da Enfermagem. São Paulo.

- Campos, P. F. S. (junho, 2011). Ata da Segunda Assembleia Geral. Academia Brasileira de História da Enfermagem. São Paulo.

- González, J.S. (2016). Teoria e Método nos Estudos Históricos em Enfemagem-o Modelo Estrutural Dialético dos Cuidados (MEDC). In Oguisso, T., Freitas, G.F. \& González, J.S. (Ed.), EnfermagemHistória, Cultura dos Cuidados e Métodos (pp. 289-315). Rio de Janeiro: Águia Dourada.

- Kuntze, T.D. (setembro, 2010). Ata da Primeira Assembleia Geral. Academia Brasileira de História da Enfermagem. Rio de Janeiro.

- Löw, L. (2013). Enfermeiras Negras na Revolução Constitucionalista de 1932. (Tese inédita de mestrado). Universidade de São Paulo, Escola de Enfermagem, São Paulo, SP.

- Oguisso, T. (2014). Trajetória histórica da enfermagem. Barueri-SP: Manole.

- Oguisso, T. (2016). Amália-Uma Gigante da Enfermagem Brasileira. Enfermagem em foco, 7 (3/4), 81-85.

- Padilha, M.I.C.S., Nazario, N. O. \& Moreira, M.C. (1997). A Compreensão do Ideário da Enfermagem para a Transformação da Prática Profissional. Revista Brasileira de Enfermagem, 50 (3), 307-322.

- Padilha, M. I. C. S. \& Borenstein, M.S. (2005). O Método de Pesquisa Histórica na Enfermagem. Texto, Contexto e Enfermagem, 14(04), 575-584.

- Primeiro Simpósio Ibero-americano de História da Enfermagem: Memória e Identidade Profissional. (2007). Livro Programa. São Paulo: Tecart. 